\title{
HUBUNGAN PERILAKU DAN TINGKAT KEPADATAN LALAT DENGAN KEJADIAN DIARE DI PASAR SARILAMAK
}

\author{
Cici Apriza Yanti ${ }^{1}$, Dina Ediana ${ }^{2}$, Mhd Rizki ${ }^{3}$ \\ ${ }^{123}$ Program Studi Ilmu Kesehatan Masyarakat STIKes Fort De Kock \\ ${ }^{1}$ Email: ciciaprizayanti@fdk.ac.id ${ }^{2}$ Email: dinaediana@ $\underline{\text { fdk.ac.id }}$
}

Submitted:11 - 4- 2018 , Reviewer: 13-4-2018 , Accepted: 28-4-2018

\begin{abstract}
Diarhea disease is one of the health problems in developing countries, especially in Indonesia. The incidence of diarrhea in West Sumatra is about $10 \%$ of the population multiplied by the national rate of illness. Diarrhea in Lima Puluh Kota District in 2014 showed an increase in cases as many as 7,017 cases. The Objective of study to correlation of incidens diarrhea among children in Sarilamak market. The type of research used is descriptive research with cross sectional approach where the independent variable is the density of flies, the behavior reduces the incidence of diarrhea and the processing and storage of food with the dependent variable is the incidence of diarrhea in toddlers around Sarilamak Market. The sample in this study amounted to 56 people. The result of the research was obtained of medium fly density level $64.3 \%$, bad respondent behavior $60.7 \%$, poor food processing and storage 33,9\% and diarrhea 35.7\%. The result of statistical test showed significant relationship between flies with diarrhea occurrence (Pvalue $=0.001)$ with $\mathrm{OR}=$ 7.694, maternal behavior with diarrhea occurrence (Pvalue $=0.034$ ) with $\mathrm{OR}=4,200=0.029$ ) with $\mathrm{OR}=4.278$. The conclusions from the study revealed that most of the respondents suffered from diarrheal diseases from the aspect of flies density, behavior and the way of processing and storage of food.
\end{abstract}

Keywords: the level of fly density, behavior, way of processing and storage of food, the occurrence of diarrhea

ABSTRAK
Penyakit diare merupakan salah satu masalah kesehatan dinegara berkembang terutama di Indonesia.Kejadian diare di Sumatera Barat sekitar 10\% dari jumlah penduduk dikalikan dengan angka kesakitan nasional. Sedangkan diare di Kabupaten Limapuluh Kota tahun 2014 menunjukan peningkatan kasus sebanyak 7.017 kasus. Tujuan penelitian ini adalah untuk mengetahui faktor - fakor yang berhubungan dengan kejadian diare pada di pasar Sarilamak. Jenis penelitian yang digunakan adalah penelitian survey dengan pendekatan cross sectional dimana variabel independent yaitu tingkat kepadatan lalat, perilaku, pengolahan serta penyimpanan makan dengan variabel dependent yaitu kejadian diare pada balita di sekitar Pasar Sarilamak. Populasi dalam penelitian ini berjumlah 56 orang. H asil penelitian yang didapatkan dari tingkat kepadatan lalat sedang $64.3 \%$, perilaku responden yang buruk $60.7 \%$, Pengolahan dan penyimpanan makanan yang buruk 33,9\% dan yang menderita diare 20 orang (35.7\%). Hasil uji statistik menunjukan hubungan bermakna anatara kepadatan lalat dengan kejadian diare dengan (Pvalue $=0.001)$ dengan $\mathrm{OR}=7.694$, perilaku ibu dengan kejadian diare di dapatkan (Pvalue $=0.034)$ dengan $\mathrm{OR}=4.200$, cara pengolahan dan penyimpanan makanan di dapatkan hasil ( $\left.\mathrm{P}_{\text {value }}=0,029\right)$ dengan $\mathrm{OR}=4.278$. Kesimpulan dari hasil penelitian menyatakan bahwa sebagian besar responden menderita penyakit diare dari aspek tingkat kepadatan lalat, perilaku serta cara pengolahan dan penyimpanan makanan. Oleh karena itu diperlukan kesadaran masyarakat tentang pola hidup bersih dan pengetahuan tentang diare.

Kata Kunci : Tingkat Kepadatan Lalat, Perilaku Ibu, Cara Pengolahan Dan Penyimpanan Makanan Dan Penyakit Diare 


\section{PENDAHULUAN}

Penyakit diare merupakan salah satu masalah kesehatan di Negara berkembang terutama di Indonesia, baik di perkotaan maupun di pedesaan. Penyakit diare bersifat endemis juga sering muncul sebagai Kejadian Luar Biasa (KLB) dan di ikuti korban yang tidak sedikit. Untuk mengatasi penyakit diare dalam masyarakat baik tata laksana kasus maupun untuk pencegahannya sudah cukup di kuasai. Akan tetapi permasalahan tentang penyakit diare masih merupakan masalah yang relatif besar (Safira, dkk. 2015).

Di Sumatera Barat jumlah prakiraan penyakit diare $10 \%$ dari jumlah penduduk dikalikan dengan angka kesakitan (angka kesakitan Nasional 214 per 1.000 penduduk). Tahun 2014 prakiraan kasus diare adalah 7.878 orang. Data program diare tahun 2014 ditemukan kasus diare 7.017 kasus atau 89.07\% dari jumlah prakiraan kasus dan angka kesakitan diare adalah sebesar 19.06 per 1.000 penduduk (DKK Profinsi Sumbar. 2014). Riskesdas 2013 memberikan data bahwa diare banyak terjadi pada kelompok umur $1-4$ tahun dan diatas 75 tahun, ini dapat dilihat dari periode prevalence pada kedua kelompok umur tersebut yaitu $12 \%$ dan $10,5 \%$.

Data kejadian diare di Kabupaten Lima Puluh kota dari tahun 2010 sampai 2014 menunjukan, bahwa dari tahun 2010 sampai 2012 terjadi penurunan kasus diare dengan angka kejadian kasus diare pada tahun 2010 sebanyak 7.958 kasus terjadi penurunan pada tahun 2011 menjadi 7.675 kasus dan penurunan signifikan pada tahun 2012 yaitu menjadi 6.176 kasus. Namun pada tahun 2013 adanya peningkatan penemuan kasus sampai tahun 2014, dengan data angka peningkatan kasus sebanyak, pada tahun
2013 ditemukan kasu diare sebanyak 6.827 kasus dan pada tahun 2014 terjadi peningkatan kasus dengan angka peningkatan sebanyak 7.017 kasus ( Profil Kesehatan Kabupaten Limapuluh Kota Tahun. 2014).

Data Puskesmas Tanjung Pati menunjukan sebanyak 12.757 orang penduduk di Nagari Sarilamak yang terdiri 6.457 orang laki-laki dan 6.300 orang perempuan, dengan target penemuan kejadian diare sebanyak 273 kejadian sedangkan yang ditemukan adalah 131 kejadian. Menurut petugas Puskesmas kebanyakan masyarakat tidak melapor atau berobat ke Puskesmas karena penyakit diare dianggap penyakit yang tidak berbahaya. Perilaku dan cara pengolahan serta penyimpanan makanan oleh ibu menunjukkan bahwa perilaku hidup bersih dalam penjamahan makanan dan penyimpanan makan yang dilakukan ibu mempunyai hubungan yang bermakna dalam mencegah terjadinya penyakit diare pada balita (Andriani. 2010).

Berdasarkan survei awal yang peneliti lakukan, Nagari Sarilamak memiliki luas wilayah $117,97 \mathrm{~km}^{2}$ yang terdiri dari 5 jorong. Nagari Sarilamak memiliki pasar tradisional yaitu Pasar Nagari Sarilamak terletak di Jorong Sarilamak, yang letaknya berada di tengah-tengah pemukiman penduduk. Jumlah warga di sekitar Pasar Sarilamak cukup tinggi, oleh karena itu warga dapat terkena dampak yang buruk karena keadaan pasar yang kotor dan tingkat kepadatan lalat yang cukup tinggi. Perilaku ibu dalam keluarga terutama dalam pengolahan dan penyimpanan makanan juga belum terlalu baik. Sehingga ibu yang memiliki balita dapat terkena dampak yaitu kejadian diare pada balita.

Dari pengamatan awal yang telah 
peneliti lakukan di dapatkan hasil tingkat kepadatan lalat yang rata-rata rendah dan sedang, dengan angka tingkat kepadatan 5.25 di TPS sampah dan 6.36 di Los jualan pada hari pasar Sabtu, 29 juli 2017. Pengukuran tingkat kepadatan lalat di 3 rumah warga yang memiliki balita didapkan hasil tingkat kepadatan lalat rendaah dan sedang yaitu 6.21, 7.3, 4.31 dan 6.52. Sedangkan jumlah ibu yang memiliki balita di sekitar Pasar Sarilamak adalah sebanyak 57 orang, setelah peneliti survei ada kejadian diare pada balita 5 orang balita dalam kurun watu 3 bulan terakhir. Berdasarkan data diatas peneliti tertarik melakukan penelitian faktor - faktor apa sajakah yang mempengaruhi kejadian diare pada Balita di pasar Sarilamak. Adapun variabel Independen adalah Perilaku dan cara pengolahan serta penyimpanan makanan oleh ibu yang memiliki balita juga masih belum baik karna ibu belum tahu cara menyimpan makanan agar tidak tercemar oleh serangga pencemar atau pencemar bahaya lain nya. Oleh karena itu peneliti tertarik meneliti tentang "Hubungan Tingkat Kepadatan Lalat, Perilaku Serta Cara Pengolahan dan Penyimpanan Makanan Denggan Kejadian Diare Pada Balita di Sekitar Pasar Sarilamak Tahun 2017”'

\section{METODOLOGI PENELITIAN}

Jenis penelitian yang digunakan adalah penelitian deskriptif dengan pendekatan cross sectional dimana variabel independent yaitu tingkat kepadatan lalat, perilaku mengurangi kejadian diare dan pengolahan serta penyimpanan makan dengan variabel dependent yaitu kejadian diare pada balita di sekitar Pasar Sarilamak dikumpulkan pada waktu bersamaan untuk melihat ada atau tidaknya hubungan tingkat kepadatan lalat dengan kejadian diare pada balita di sekitar Pasar Sarilamak.

Penelitian ini dilaksanakan pada bulan Agustus 2017 di Pasar Sarilamak dan rumah warga di sekitar Pasar Sarilamak Populasi dalam penelitian ini adalah seluruh titik yang dijadikan untuk mengukur tingkat kepadatan lalat di Pasar Sarilamak dan rumah warga di sekitar Pasar Sarilamak, Selanjutnya seluruh ibu yang memiliki balita di sekitar Pasar Sarilamak yang berjumlah 57 orang ibu yang memiliki balita. Instrumen penelitian ini adalah dengan menggunakan kuesioner dan wawancara terpimpin kepada seluruh responden, sedangkan untuk kepadatan lalat dengan menggunakan flygrill.

Variabel independen adalah tingkat kepadatan lalat yaitu: rata lalat yang hinggap pada setiap block grill per satuan waktu di titik pengukuran kepadatan lalat di rumah warga sekitar Pasar sarilamak, Perilaku Ibu yaitu: tindakan yang dilakukan oleh ibu berdasarkan kesadaran untuk mengurangi atau meningkatkan kebersihan dan kedisiplinan yang diasrkan oleh pendidikan dan pengetahuan ibu, Cara pengolahan dan penyimpanan makanan Upaya yang ditujukan untuk meningkat kan kebersihan pada makanan agar makanan tidak tercemar oleh pencemar makanan. Variabel dependen kejadian diare Keadaaan balita mengalami buang air besar cair atau mencret dengan frekuensi lebih dari 3 kali dalam sehari dalam kurun waktu 3 bulan terakhir. Dengan batasan umur 1-5 tahun.

\section{HASIL DAN PEMBAHASAN}

Berdasarkan hasil penyebaran kuesioner kepada seluruh responden dan melakukan penghitungan jumlah lalat dengan menggunakan flygrill didapatkanlah hasil penelitian sebagai berikut: 


\section{Analisis Univariat}

\begin{tabular}{llcc}
\hline No & \multicolumn{1}{c}{ Variabel } & f & \% \\
\hline 1 & Kepadatan lalat & & \\
& Sedang & 36 & 64,3 \\
& Rendah & 20 & 35,7 \\
2 & Perilaku & & \\
& Buruk & 34 & 60,7 \\
& Baik & 22 & 39,3 \\
3 & Pengolahan dan penyimpanan makanan & & \\
& Buruk & 19 & 33.9 \\
& Baik & 37 & 66.1 \\
4 & & \\
& Kejadian Diare & 20 & 35.7 \\
& Diare & 36 & 64.3 \\
& Tidak Diare & $\mathbf{5 6}$ & $\mathbf{1 0 0}$ \\
\hline & Jumlah & & \\
& &
\end{tabular}

Distribusi frekuensi kepadatan lalat terhadap kejadian diare adalah balita yang bermukim disekitar pasar Sarilamak yaitu rumah responden dengan tingkat kepadatan lalat sedang dengan jumlah 36 orang (64.3\%). Untuk mengetahui angka kepadatan lalat di suatu wilayah dilakukan dengan cara mengukur angka tingkat kepadatan lalat tersebut dengan menggunakan flygrill yang diletakkan pada tempat yang akan kita ukur kepadatannya, setelah itu kita hitung berapa jumlah lalat yang hinggap pada flygrill dengan menggunakan counter.

Kita juga perlu mengukur kelambaban dan kecepatan anggin pada tempat kita melakukan pengukuran (Depkes RI. 2010). Kepadaan lalat akan semakin tinggi di tempat yang kotor karna disana tersedia makanan dan tempat berkembang biak bagi lalat. Lalat betah hidup di tempat yang kotor seperti TPS sampah, los jualan dan pertokoan di pasar. Hal ini berpengaruh terhadap warga yang tinggal disekitar Pasar Sarilamak karena lalat dapat terbang kerumah warga mencari makanan dan tempat berkembang biak.
Pada penelitian ini menunjukkan bahwa tidak semua ibu memiliki perilaku buruk dibandingkan dengan ibu yang memiliki perilaku baik. Jika dilihat dari prilaku responden, didapatkan responden banyak memiliki prilaku buruk sebanyak 34 orang $(60.7 \%)$ dibandingkan dengan responden yang memiliki prilaku baik sebanyak 22 orang (39.3\%). Perilaku buruk ibu seperti tidak memasak air minum dengan jumlah 29 orang $(51,7 \%)$ dan tidak mencuci tangan sebelum memberi makan balita sebanyak 39 orang $(69,6 \%)$. Perilaku ibu yang buruk ini terjadi akibat rendahnya pengetahuan ibu, seperti ibu tidak mengetahui apa yang terjadi pada anak yang diare sebanyak 29 orang $(51.7 \%)$, jenis makanan seperti apa untuk anak yang diare sebanyak 35 orang (62.5\%) dan apa penyebab diare masih ada 20 orang ibu (35.7\%) . Peneliti berasumsi bahwa perilaku, sikap, dan tindakan ibu yang buruk dari ibu yang memiliki balita terjadi karena rendahnya tingkat pengetahuan ibu, sehingga berpengaruh terhadap tindakan ibu yang buruk. 
Hasil penelitian yang sudah dilakukan dapat diketahui sebagian besar pengelolaan dan penyimpanan makanan responden sudah baik, ada sebagian yang perilaku pengolahan dan penyimpanan makanan ibu yang masih buruk. Perilaku ibu yang buruk hanya beberapa saja yang didapatkan diantaranya tidak memakai perlengkapan memasak sebanyak 50 orang $(89.2 \%)$, tidak membersihkan tempat pengolahan makanan sebanyak 23 orang $(41.07 \%)$ dan menyimpan makanan lebih dari dua hari sebanyak 34 orang (60.7\%).

Peneliti beransumsi bahwa pengelolaan dan penyimpanan makana yang baik seperti mencuci bahan makan sebelum dimasak sebanyak 56 orang (100\%), meletakkan makan sudah jadi di wadah yang bersih sebanyak 53 orang $(94.6 \%)$ dan menyimpan makanan pada tempat tertutup sebanyak 47 orang (83.9\%).

Pengolahan dan penyimpanan makanan yang baik atau terhindar dari pencemar yang dapat mencemari makan akan meningkatkan tingkat kebersihan dan kesterilan pada makanan yang dikonsumsi. Berdasarkan analisa penelitian diperoleh gambaran distribusi frekuensi kejadian diare pada balita yang bermukim di sekitar pasar sarilamk dengan responden yang tidak diare sebanyak 36 orang (64.3\%). Diare diartikan sebagai buang air encer lebih dari empat kali sehari, baik disertai lendir dan darah maupun tidak.

Hingga kini diare masih menjadi child killer (pembunuh anak-anak) peringkat pertama di Indonesia. Semua kelompok usiadiserang oleh diare, baik balita, anak-anak dan orang dewasa.(Christy, 2014) Tetapi penyakit diare berat dengan kematian yang tinggi terutama terjadi pada bayi dan anak balita (Suharyono. 2012). Pencegahan diare penting disebarluaskan karena sangat membantu dalam penanganan pertama pada anak yang mengalami diare. Untuk itu perlu adanya pendidikan kesehatan dan pelatihan tentang apa itu diare, penyebab, dan cara penanganan dirumah terhadap diare kepada petugas kesehatan, kader kesehatan bahkan ibu-ibu rumah tangga. Perlunya dibina atau ditingkatkan kerjasama yang baik antara lintas sektoral dan lintas program di dalam puskesmas demi peningkatan pengetahuan dan meningkatnya derajat kesehatan masyarakat.

\section{Analisis Bivariat}

\begin{tabular}{|c|c|c|c|c|c|c|c|c|c|}
\hline \multirow{3}{*}{ No } & \multirow{3}{*}{ Variabel } & \multicolumn{4}{|c|}{ Kejadian Diare } & \multicolumn{2}{|c|}{ Total } & \multirow{3}{*}{$\mathbf{p}_{\text {value }}$} & \multirow{3}{*}{$\begin{array}{c}\text { OR } \\
(95 \% \\
\text { CI }) \\
\end{array}$} \\
\hline & & \multicolumn{2}{|c|}{ Diare } & \multicolumn{2}{|c|}{ Tidak } & \multirow{2}{*}{$\mathbf{n}$} & \multirow{2}{*}{$\%$} & & \\
\hline & & $\mathbf{n}$ & $\%$ & $\mathbf{n}$ & $\%$ & & & & \\
\hline \multirow[t]{3}{*}{1.} & Kepadatan Lalat & & & & & & & & \\
\hline & Sedang & 7 & 19,49 & 29 & 80,6 & 36 & 100 & \multirow[t]{2}{*}{0,001} & \multirow{2}{*}{$\begin{array}{l}7,694- \\
26,458\end{array}$} \\
\hline & Rendah & 13 & 65,0 & 7 & 35,0 & 20 & 100 & & \\
\hline \multirow[t]{3}{*}{2.} & Perilaku & & & & & & & & \\
\hline & Buruk & 15 & 50 & 15 & 50 & 30 & 100 & \multirow[t]{2}{*}{0,034} & 4,200 \\
\hline & Baik & 5 & 19,2 & 21 & 80,4 & 26 & 100 & & $\begin{array}{l}(1,253- \\
14,081)\end{array}$ \\
\hline \multirow[t]{4}{*}{3.} & Pengolahan dan pe & nak & & & & & & & \\
\hline & Buruk & 11 & 57,9 & 8 & 42,1 & 19 & 100 & \multirow[t]{2}{*}{0,029} & 4,278 \\
\hline & Baik & 9 & 24,3 & 28 & 75,7 & 37 & 100 & & $\begin{array}{l}(1,314- \\
13,928)\end{array}$ \\
\hline & Jumlah & 20 & 35,7 & 36 & 64,3 & 56 & 100 & & \\
\hline
\end{tabular}


Hasil penelitian menunjukkan total kepadatan lalat sedang adalah 36 rumah ibu yang memiliki balita dan yang menderita diare adalah sebanyak 7 orang (19.4\%) sedangkan rumah ibu yang memiliki balita dengan tingkat kepadatan lalat rendah berjumlah 20 rumah dan yang menderita diare adalah sebanyak 13 orang (65.0\%). Hasil uji staistik ini menunjukkan terdapat hubungan yang bermakna antara kepadatan lalat dengan kejadian penyakit diare dengan $\left(\mathrm{P}_{\text {value }}=0,001\right)$.

Kepadatan lalat berpeluang untuk terjadinya penyakit diare dengan $\mathrm{OR}=$ 7.694. Dengan kata lain dapat disimpulkan bahwa kepadatan lalat sedang berpeluang 7 kali untuk terjadinya penyakit diare dibandingkan dengan kepadatan lalat rendah. Menurut asumsi peneliti mengurangi atau menghilangkan tempat perindukan lalat dapat dilakukan, upaya perbaikan hygiene dan sanitasi lingkungan rumah atau meningkatkan kesadaran masyarakat terhadap kebutuhan akan lingkungan yang bersih, penataan hunian rumah yang sehat.

Selain itu, perlunya melindungi makanan, peralatan makan, dan orang yang kontak dengan lalat dapat dilakukan dengan cara: jendela dan ventilasi rumah dipasang kawat kasa, pintu masuk dilengkapi dengan gorden, penggunaan tudung saji untuk menutup makanan, dan memasang stik perekat anti lalat jika diperlukan untuk mencegah atau mengurangi lalat masuk ke dalam rumah dan mengurangi bahaya terhadap kontaminasi makanan oleh lalat. Bisa juga dengan usaha pengendalian dengan menggunakan Insektisida sesuai aturan pemakaian.

Hasil penelitian menunjukkan total jumlah ibu yang berprilaku buruk adalah sebanyak 30 orang yang kejadian diare pada balita sebanding yaitu 15 orang (50\%) balita yang diare dan balita tidak diare 15 orang $(50 \%)$. Sedangkan ibu yang berprilaku baik berjumlah 26 orang dengan kejadian diare pada balita hanya 5 orang (19.2\%). Dari hasil uji dapat dilihat adanya hubungan yang bermakna antara prilaku ibu dengan kejadian penyakit diare dengan $\left(\mathrm{P}_{\text {value }}=\right.$ 0,034). Prilaku ibu berpeluang untuk terjadinya penyakit diare dengan $\mathrm{OR}=$ 4.200. Dengan kata lain dapat disimpulkan bahwa prilaku ibu yang berprilaku buruk berpeluang 4 kali untuk terjadinya penyakit diare dibandingkan dengan prilaku ibu yang berprilaku lebih baik. Berdasarkan asumsi peneliti hasil penelitian menunjukkan bahwa tidak semua ibu memiliki perilaku buruk, namun perilaku, sikap dan tindakan ibu yang buruk dari ibu berengaruh terhadap kejadian diare.

Pada penelitian ini jika dilihat dari prilaku responden, didapatkan responden banyak memiliki prilaku buruk dibandingkan dibandingkan dengan responden yang memiliki prilaku tinggi, dalam hal ini peneliti berasumsi bahwa responden banyak berprilaku kurang baik dan tidak memiliki sikap yang baik juga,kurangnya sikap dan tindakan dari ibu akan memberi peulang yang besar untuk tingkat kejdian diare. Jadi untuk ibu yang mengetahui bahaya keoadatan lalat agar berprilaku lebih baik lagi.

Hasil penelitian menunjukkan total jumlah pengolahan dan penyimpanan makan yang baik adalah 19 orang dan yang menderita diare adalah 11 orang $(57.9 \%)$ sedangkan yang tidak diare adalah sebanyak 8 orang (42.1). Sedangkan ibu yang pengolahan dan penyimpanan makanan nya baik berjumlah 37 orang dan yang menderita diare hanya 9 orang (24.3\%) sedangkan 
yang tidak diare adalah sebanyak 28 orang $(75.7 \%)$. Dari hasil uji statistik dapat dilihat terdapat hubungan yang bermakna antara pengelolaan dan penyimpanan makan dengan kejadian penyakit diare dengan $\left(\mathrm{P}_{\text {value }}=\right.$

$$
\text { 0,029). Pengelolaan dan }
$$

penyimpanan makan yang buruk berpeluang untuk terjadinya penyakit diare dengan $\mathrm{OR}=4.278$. Dengan kata lain dapat disimpulkan bahwa pengelolaan dan penyimpanan makan buruk berpeluang 4 kali untuk terjadinya penyakit diare dibandingkan pengelolaan dan penyimpanan makan baik.

Dalam penelitian ini responden lebih banyak yang ibu yang pengolahan dan penyimpanan makanannya baik, peneliti beransumsi bahwa pengelolaan dan penyimpanan makanan oleh ibu yang lebih baik seperti mencuci bahan makan sebelum dimasak, meletakkan makan sudah jadi di wadah yang bersih dan menyimpan makanan pada tempat tertutup, dapat mengurangi keterjadian penyakit diare pada balita.(Rahman, Widoyo, Siswanto, \& Biantoro, 2016). Makanan yang sudah bersih saat diolah dan di simpan akan mengurangi angka bakteriologi yang dapat menyebabkan penyakit diare pada balita, dewasa atau lansia. Sedangkan pengolan dan penyimpanan makanan yang buruk maka akan beresiko terhadap kejadian penyakit diare karena bakteri yang ada pada makanan dan bakteri yang ada pada lalat jika mencemari makanan akan dapat menyebabkan diare.(Safira, Nurmanini, \& Al, 2015)

\section{SIMPULAN}

Berdasarkan tujuan dan hasil penelitian mengenai hubungan tingkat kepadatan lalat, perilaku serta pengolahan dan penyimpanan makanan dengan kejadian diare pada balita bermukim di sekitar Pasar sarilamak Tahun 2017, maka dapat ditarik kesimpulan sebagai berikut: Terdapat sebagian besar responden mengalami penyakit diare yang paling banyak adalah dengan tingkat kepadatan lalat sedang yaitu sebanyak $64.3 \%$.

Terdapat lebih dari sebagian responden mengalami penyakit diare yang paling banyak adalah dengan tingkat prilaku ibu buruk yaitu sebanyak $60.7 \%$. Terdapat sebaagian besar responden mengalami penyakit diare yang paling banyak adalah dengan tingkat pengelolaan dan penyimpanan makanan baik yaitu sebanyak 37 orang $(66.1 \%)$.

Terdapat $56 \quad$ responden sebaagian besar responden tidak mengalami penyakit diare yaitu dengan jumlah 36 orang (64.3\%). Terdapat hubungan signifikan antara kepadatan lalat dengan kejadian penyakit diare pada balita bermukim di sekitar pasar sarilamak dengan $\left(\mathrm{P}_{\text {value }}=0,001\right)$.

Kepadatan lalat berpeluang untuk terjadinya penyakit diare dengan $\mathrm{OR}=$ 7.694. Terdapat hubungan signifikan antara prilaku ibu dengan kejadian penyakit diare pada balita bermukim di sekitar pasar sarilamak dengan $\left(\mathrm{P}_{\text {value }}=0,025\right)$. Prilaku ibu berpeluang untuk terjadinya penyakit diare dengan $\mathrm{OR}=4.200$. Terdapat hubungan signifikan antara pengelolaan dan penyimpanan makan dengan kejadian penyakit diare pada balita bermukim di sekitar pasar sarilamak dengan $\left(\mathrm{P}_{\text {value }}=0,019\right)$. 
pengelolaan dan penyimpanan makan rendah berpeluang untuk terjadinya penyakit diare dengan $\mathrm{OR}=4.278$.

Diharapkan bagi petugas atau pengelola pasar Sarilamak melakukan pemantauan terhadap semua titik mulai dari TPS, los daging dan los sayur yang mungkin akan menjadi tempat beristihat dan berkembang biaknya lalat. karena banyaknya sisa-sisa sampah hasil kegiatan pasar yang menumpuk pada TPS dan los tempat berjualan dengan melakukan penataan ulang di pasar Sarilamak agar tingkat kebersihan pasar lebih baik dan dapat mencegah tingkat kepadatan lalat.

\section{UCAPAN TERIMAKASIH}

Dalam proses penelitian ini penulis banyak mendapat masukan, bantuan, dukungan, bantuan dan arahan dari berbagai pihak, untuk itu dengan segala kerendahan hati dan penuh penghargaan penulis mengucapkan terima kasih yang tidak terhingga kepada semua pihk yang telah banyak membantu. Kepada pihak pengelola pasar yag telah mengizinkan kepada penulis untuk melakukan penelitian. Serta kepada pihak Dinas kesehatan Lima Puluh Kota terkhusus kepada Puskesmas Tanjung Pati yang telah membrikan bantuan data sekunder sebagai landasan bagi penulis dalam menyelesaika laporan penelitian ini. Kepada Responden yang telah berpartisipasi dalam penelitian.

\section{DAFTAR PUSTAKA}

Andriani. 2010. Analisis Faktor Resiko Kejadian Diare Pada Anak Usia Dibawah 2Tahun di RSUD Koja Jakarta. Jakarta. Universitas Indonesia.

Aristin, I. 2015. Pengaruh Faktor Lingkungan dan Perilaku
Pengolahan Makanan Terhadap

Kejadian Diare. Jurnal

Kesehatan Lingkungan Poltekkes

Denpasar.

Chandra, B. 2010. Ilmu Kesehatan Masyarakat Dalam Konteks

Kesehatan Lingkungan. Jakarta: EGC

Christy, M. Y. (2014). Factors Associated with Diarrheal Dehydration in Toddlers at Kalijudan Health Center Work Area. Jurnal Berkala Epidemiologi, 2(3), 297-308.

Depkes RI. 2010. Pemberantasan Serangga Dan Binatang Pengerat. Jakarta.

Dinas Kesehatan Kabupaten Limapuluh Kota. 2014. Profil Kesehatan Kabupaten Limapuluh Kota. Sarilamak. DKK Limapuluh Kota.

Dinas Kesehatan Profinsi Sumbar. 2014. Profil Kesehatan Sumbar. Padang.

Dinas Kesehatan. Depkes RI. 2011. Pedoman Pencegahan Dan Pengobatan Diare. Jakarta. Direktorat Jendral Pelayanan Medik Departemen Kesehatan Republik Indonesia.

Direktorat Jendral Pengendalian Lingkungan Departemen Kesehatan Republik Indonesia.

Dianing, W, P. 2011. Hubungan Tingkat Kepadatan Lalat (Musca Domestica) Dengan Kejadian Diare Pada Anak Balita Di Pemukiman Di Sekitar TPA Namo Bintang Kecamatan Pancur Batu Kabupaten Deli Serdang. Fakultas Kesehatan Masyarakat Universita Sumatera Utara.

Hastutiek, P. 2007. Potensi musca domestica Sebagai Vektor Beberapa Penyakit. Jurnal Kedokteran Universitas Brawijiya Malang. Vol. XXIII, No. 3 
Kamila, L, dkk. 2012. Hubungan Praktek Personal Hygiene Ibu Dan Kondisi Sanitaasi Lingkungan Rumah Dengan Kejadian Diare Pada Balita Di Puskesmas Kampung Dalam Kecamatan Pontianak Timur. Jurnal Kesehatan Lingkungan Indonesia. Vol. 11, No. 2

Kemenkes RI. 2011. Profil Kesehatan Indonesia 2011. Jakarta. Kementerian Kesehatan Republik Indonesia.

Mauliku, N, dkk. 2010. Hubungn Antara Perilaku Ibu Dengan Kejadian Diare Pada Balita Di Puskesmas Batujajar Kabupaten Bandung Barat. Kesehatan Masyarakat STIKes Ahmad Yani.

Naimah, N, dkk. 2013. Hubungan Tingkat Pengetahuan Ibu Tentang Hygiene Sanitasi Dengan Kejadian Diare Pada Balita Di Puskesmas Jati Bogor. Kebidanan Politeknek Harapan Baersama.

Notoatmodjo, S.2015. Kesehatan Massyarakat Ilmu \& Seni. Jakarta: Rineka Cipta. Pratama, N,R. 2013. Hubungan Antara Sanitasi Lingkungan Dan Personal Hygiene Ibu Denagan Kejadian Diare Pada Balita Di Kelurahan Sumurejo Kecamatan Gunungpati Kota Semarang. Jurnal Kesehatan Masyarakat UNDIP. Vol. 2, No. 1

Rahman, H. F., Widoyo, S., Siswanto, H., \& Biantoro. (2016). Faktor-Faktor Yang Berhubungan Dengan Kejadian Diare Di Desa Solor Kecamatan Cermee Bondowoso. NurseLine Journal, 1(1).

Riset Kesehatan Dasar. 2013. Angka Kejadian Penyakit di Masyarakat.
Padang.

Safira, S., Nurmanini, \& Al, E. (2015). Hubungan Kepadatan Lalat,Personal Higiene Dan Sanitasi Dasar Dengan Kejadian Diare Pada Balitadi Lingkungan Kelurahan Paya Pasir Kecamatan Medan Marela. Journal Usu, 4(3), 1-10.

Suraatmaja. 2007. Pengantar Kesehatan Lingkungan. Jakarta. Rifindo Cipta.

Suandi. 2009. Pengantar Kesehatan Lingkungan: Jakarta: Kedokteran. EGC Widoyono. 2008. DasarDasar Penyakit Berbasis Lingkungan. Jakarta: PT Rajagrafindo Persada.

Wulansari, E. 2012. Jurnal Ekologi Kesehatan Vol 3 No 3. 128-135. 
